$\underline{\text { Research Article }}$

\title{
Correlation of clinical outcome with laboratory parameters in children with dengue infection: An appraisal from a tertiary children's hospital in India
}

\author{
K. Rameshkumar ${ }^{1}$, CP Raghuram ${ }^{1}$ \\ Sri Lankan Journal of Infectious Diseases 2020 Vol.10 (1):48-52 \\ DOI: http://doi.org/10.4038/sljid.v10i1.8266
}

\begin{abstract}
Introduction: Dengue infection is caused by the dengue virus (arbovirus), the incidence of which is increasing in India. In dengue endemic settings, early diagnosis and monitoring for complications are important, especially in children. Concurrent testing of NSI antigen, dengue specific IgG and IgM will help to diagnose patients with suspected dengue fever.
\end{abstract}

Objective: To correlate the clinical profile and outcome of dengue fever with detection of NSI antigen, dengue specific IgG and IgM antibody, hematological and biochemical parameters and blood component utilization.

Methods: All children presenting to Rainbow hospital and diagnosed with dengue infection using NS1 and dengue specific $\operatorname{IgG}$ and $\operatorname{IgM}$ antibody during a one year period ( $1^{\text {st }}$ November 2016 to $31^{\text {st }}$ October 2017) were included in the study. The haemogram and biochemistry parameters were done using automated analyzers. Inpatients were classified as severe or nonsevere based on clinical and/or laboratory evidence. The degree of association between clinical parameters and disease severity in relation to NS1 positivity was expressed as an odds ratio.

Results: Among 213 children diagnosed, 126 were treated as inpatients and the rest as outpatients. The age range of the study sample was 6 months to 15 years. NS1 positivity was observed in $72.3 \%$ patients. NS1 positivity, when compared to severity of disease was significant (Odds ratio: $2.3 ; \mathrm{p}<.05$ ). One death was reported in the severe group. Chi square test applied to assess the correlation of platelet count and NS1 positivity was also significant ( $\mathrm{Z}$ score: $3.8 \mathrm{p}<.05$ ). Among the NS1 positive patients, in $8.5 \%$ (7) patients, very severe thrombocytopenia of $<25000$ cells $/ \mathrm{mm}^{3}$ was observed.

Conclusions: Using all three tests (NS1, dengue specific $\operatorname{IgM}$ and $\operatorname{IgG}$ ) was useful, as in 59 (27.7\%) patients, despite a negative NS1, based on a positive dengue antibody response (IgG and/or IgM), the patients were admitted and monitored. NS1 positivity was associated with a higher risk of thrombocytopenia in this study.

Keywords: Dengue, NSI positivity, Thrombocytopenia, Blood transfusion

\begin{tabular}{l}
${ }^{1}$ Rainbow Children's Hospital, Bangalore-India \\
\hline Address for correspondence: Dr. Karuna Rameshkumar, Pathologist, Rainbow children's hospital, Bangalore, \\
India. Telephone: +918026681974 Email:karunark@yahoo.com (i) http://orcid.org/0000-0003-4340-4948
\end{tabular} Received 12 September 2019 and revised version accepted 6 February 2020 


\section{Introduction}

Dengue infection is an arboviral disease caused by the dengue virus. Dengue is increasing in incidence in India and is associated with significant morbidity and mortality. ${ }^{1}$ In India, the annual incidence is estimated to be 7.5 to 32.5 million. ${ }^{1,2}$ At present there is no effective antiviral treatment or vaccine to prevent infections. In a dengue endemic setting, early diagnosis and monitoring for complications are important. There are very few studies in India based on the revised WHO dengue classification for management. ${ }^{3,4,5}$

The objective of this study was to correlate the patient clinical profile and outcome with detection of NSI antigen, dengue $\operatorname{IgG}$ and $\operatorname{IgM}$ antibody detection and other laboratory parameters, and to evaluate clinical parameters and blood component utilization.

\section{Materials and methods}

The study was a retrospective observational study from $1^{\text {st }}$ November 2016 to $31^{\text {st }}$ October 2017. During this one year period, all children with fever who were suspected to have infection including dengue were included. The children who were positive for malaria, meningitis, and enteric fever were then excluded from the study. NS1 positivity and /or IgM positivity was used for the diagnosis of a current dengue infection. Children with fever who were either NS1 positive and/ or dengue specific IgM positive were included in the study. IgG positivity was considered along with NS1 or IgM as an indicator of infection.

NS1, IgG and IgM detection were done as per manufacturer's instructions (SD Bioline). The haemogram and biochemical parameters were done using automated analyzers (Sysmex XN and Vitros). A manual platelet count was done whenever required to confirm low values. Thrombocytopenia was defined for the study as mild when the platelet count was 75000 cells $/ \mathrm{mm}^{3}$ to 140,000 cells $/ \mathrm{mm}^{3}$, moderate $50000-75000$ cells $/ \mathrm{mm}^{3}$, severe $-25000-50000 /$ $\mathrm{mm}^{3}$ and very severe $<25000$ cells $/ \mathrm{mm}^{3}$

Inpatients were further classified as severe and non-severe based on evidence of fluid leakage (clinical / radiological/ rise in hematocrit of $>20 \%$ of baseline), platelet levels ( $<25000$ cells/ cubic $\mathrm{mm}$ ), the presence of bleeding manifestations and/or any evidence of organ damage. All patients were monitored daily till clinical and haematological improvement was seen. The degree of association between clinical parameters and disease severity was expressed as an Odds ratio. Chi square test was applied to assess the significance of presence of severe thrombocytopenia in NS1 positive patients. The blood component utilization was correlated with platelet count and hemoglobin levels for monitoring the patient's status.

\section{Results}

A total of 213 children were diagnosed with acute dengue infection during the study period, among whom 126 were treated as inpatients and the rest as outpatients based on clinical and laboratory parameters. The age of the study sample was 6 months to 15 years. The maximum number of children were in the age group of 4-9 years. (Figure 1).

Fever was present in all cases. The other chief symptoms observed were myalgia and abdominal pain.

NS1 positivity was observed in $72.3 \%$ patients. 


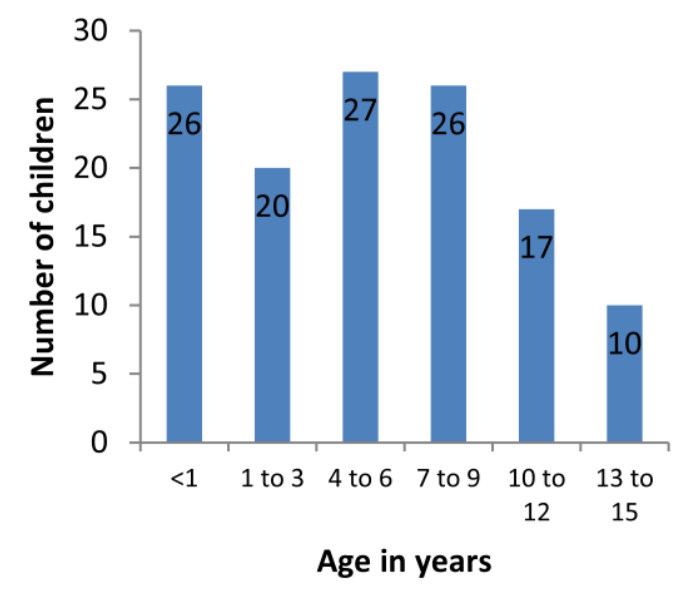

Figure 1: The incidence in different age groups.

Thrombocytopenia was present in 41 (33\%) inpatients including both NS1 positive and negative patients. Among the NS1 positive patients, in 7 (8.5\%), very severe thrombocytopenia of $<25000$ cells $/ \mathrm{mm}^{3}$ was noted. Mild thrombocytopenia was observed in $17 \%$ of NS1 positive patients and $29.5 \%$ of NS1 negative patients. Ten (7.8\%) patients had haemoglobin ( $\mathrm{Hb})$ levels below $10 \mathrm{gm} / \mathrm{dl}$ at the time of admission while no patients with severe anemia $(\mathrm{Hb}<6 \mathrm{gms} / \mathrm{dl})$ were observed. The lowest $\mathrm{Hb}$ level observed was $7.8 \mathrm{gms} / \mathrm{dl}$ in a patient in the severe group who received one unit of packed red cell concentrate (PRBC) and one unit of fresh frozen plasma (FFP). Three of the patients in the severe group required platelet transfusions while others had packed RBCs and/or FFPs (Table 1).

The degree of association between clinical parameters and disease severity in reference to NS1 positivity expressed as odds ratio was $2.3(\mathrm{p}<.05)$. Severe thrombocytopenia was significantly associated with NS1 positivity (Z score: $3.8 \mathrm{p}<.05)$.

Table 1: Details of blood components given

\begin{tabular}{|c|c|c|c|c|l|c|c|}
\hline No & $\begin{array}{c}\text { Age } \\
\text { in } \\
\text { years }\end{array}$ & $\begin{array}{c}\text { Classify } \\
\text { S/NS }\end{array}$ & $\begin{array}{c}\text { Haemoglobin } \\
\text { gms/dl }\end{array}$ & $\begin{array}{c}\text { Platelet } \\
\text { count } \\
\text { cells/ } \\
\mathbf{m m}^{3}\end{array}$ & $\begin{array}{c}\text { Blood } \\
\text { components } \\
\text { given }\end{array}$ & Positivity & $\begin{array}{c}\text { duration of } \\
\text { hospital stay } \\
\text { (days) }\end{array}$ \\
\hline 1 & 6 & NS & 9.1 & 1.35 & 1 PRBC & NS 1, & 10 \\
\hline 2 & $9 / 12$ & NS & 7.9 & 0.40 & $\begin{array}{l}\text { 1PRBC, 1FFP, } \\
\text { 1Cryo }\end{array}$ & NS1 and IgM & 10 \\
\hline 3 & 3 & NS & 7.8 & 0.57 & $\begin{array}{l}\text { 2PRBC, 1FFP, } \\
\text { 2Cryo }\end{array}$ & NS1 & 12 \\
\hline 4 & 8 & S & 8.6 & 0.15 & $\begin{array}{l}\text { 1PRBC,2FFP,1 } \\
\text { RDP }\end{array}$ & NSI and IgG & 8 \\
\hline 5 & 6 & S & 17.1 & 0.48 & $\begin{array}{l}\text { 5FFP, 2RDP, } \\
\text { 3Cryo }\end{array}$ & NS1 & 4 \\
\hline 6 & $9 / 12$ & S & 13.8 & 0.36 & 1PRBC,1RDP & NS1 & 14 \\
\hline 7 & $10 / 12$ & NS & 15.3 & 0.69 & PRBC & NS1 & 10 \\
\hline
\end{tabular}

NS- non severe, S- severe: PRBC- Packed red cell concentrate $\quad$ FFP- Fresh frozen plasma; Cryo- Cryoprecipitate RDP - Random donor platelets S- Severe NS- Non severe 
The hospital stays of patients in the severe group ranged from 4-14 days, while in the nonsevere group, the maximum stay was 5 days (Table 1) One death was reported in the severe group.

\section{Discussion}

Dengue fever is a major public health problem in India. ${ }^{3}$ The first patient with dengue fever in India was reported in 1956 from Vellore and the first patient with dengue hemorrhagic fever occurred in Calcutta in 1963. ${ }^{1}$ In Odisha, a State in Eastern India, the first outbreak was reported in 2010, followed by extensive outbreaks in 2011, affecting a large number of people. ${ }^{2}$ Dengue fever can be diagnosed using various diagnostic methods such as isolation of the virus and RT-PCR. ${ }^{4}$ In India, serological methods are used, the common ones being detection of NS1 antigen and dengue specific IgM/ IgG antibody.

Timely diagnosis is important to implement supportive therapy and monitoring. Garg et al concluded in their study on diagnostic kits that NS1 antigen detection by a rapid method is reliable for diagnosis of early acute dengue fever. They also recommended that ELISA should be done for sero diagnosis. ${ }^{6}$

The present study focused on the pediatric age group and is the largest series exclusively from South India. The children were diagnosed based on the triad testing using NS1 antigen and dengue specific $\operatorname{IgG}$ and $\operatorname{IgM}$ antibody and treated as per the new WHO management guidelines. ${ }^{5}$ The presentation of fever as the main symptom was similar to another study in India with a cohort of 97 children in the state of Odisha. ${ }^{2}$ The incidence was more in the 4-6 year age group in contrast to the reported literature which is 8.7 years. $^{2}$

NS1 antigen (a non-structural protein of the dengue virus) rapid detection test can potentially be used as a simple investigation which can diagnose dengue infection. ${ }^{6}$ While NS1 is more specific, an IgM and/or IgG antibody response can also be seen which could last several weeks to month, as in other viral infections such as Chikungunya ${ }^{7}$, resulting in misdiagnosis.

Detection of the dengue virus by virus isolation or by nucleic acid detection methods are considered as confirmatory tests for the diagnosis of dengue infection. ${ }^{8}$ However, due to the need for advanced laboratory facilities these two methods may not be suitable for routine diagnosis of dengue virus infection early in the disease in resource poor communities. Many commercial assays are currently available for the detection of dengue NS1 antigen. ${ }^{8,9,10}$ Among these tests, the Panbio early dengue NS1 capture ELISA has been shown to have an overall sensitivity of 60.4 to $66 \%$ and a specificity of 97.9 to $99 \%{ }^{8}$. It has also been shown that NS1 rapid antigen detection tests (SD Diagnostics, Bioline, South Korea) have a sensitivity of $81.6 \%$ and a specificity of $92 \%$. Hence NS1 negative patients also require follow up when these diagnostic tests are used.

Concurrent testing of NS1, dengue specific IgM and IgG and platelet count helped in early differential diagnosis and intervention of $126(59.1 \%)$ patients in the current study. Although $34(27 \%)$ patients were NS1 negative, based on IgM results, they were followed up and symptomatically treated.

Progressive leucopenia and rapid decline in platelet counts are known to precede plasma leakage. As the association of platelet count and NS1 positivity was significant (Z score:3.8 $\mathrm{p}<.05)$ it can be suggested that NS1 positivity is associated with higher risk of thrombocytopenia. 


\section{Conclusions}

The triad of testing all three (NS1, dengue specific $\operatorname{IgM} / \mathrm{IgG}$ ) markers was useful, as in 59 (27.7\%) patients, in spite of a negative NS1, based on IgG and/or IgM, the patients were admitted and/or monitored. NS1 positivity was associated with higher risk of thrombocytopenia. The results of this study suggest that the diagnosis of dengue fever may be missed in children presenting with fever with the use of only NSI or the available dengue antibody kits. Hence use of all 3 tests is recommended in children suspected of having dengue.

\section{References}

1. Gupta N, Srivatsava S, Jain A, Chaturvedi U.C. Dengue in India. IJMR 2012; 136: 373390. PMID: 23041731.

2. Shubhankar Mishra, Ramya Ramanathan, and Sunil kumar Agarwal. Clinical profile of dengue fever in children: a study from southern Odisha, India.

Scientifica 2016; Article ID 6391594:1-6 doi: https://doi.org /10.1155/2016/6391594

3. Ganesh Kumar P, Murhekar MV, Poornima V, et al. Dengue infection in India: A systematic review and meta-analysis. PLoS Negl Trop Dis 2018; 12(7):e0006618.

doi:10.1371/journal.pntd.0006618

4. Barniol, J., Gaczkowski, R., Barbato, E.V. et al. Usefulness and applicability of the revised dengue case classification by disease: multi-centre study in 18 countries. BMC Infect Dis 2011; 11:106 doi: https://doi.org/10.1186/1471-2334-11-106

5. World Health Organization. Geneva, Switzerland: WHO; 2009. Dengue: Guidelines for Diagnosis, Treatment, Prevention and Control. http://whqlibdoc.who.int/publications/2009/9789241547871_eng.pdf

6. Atul Garg, Jaya Garg, Dharam Veer Singh, and TN Dhole. Can rapid dengue diagnostic kits be trusted? A comparative study of commercially available rapid kits for sero diagnosis of dengue fever. J. Lab. Physicians.2019; 11:63-67 doi:10.4103/JLP.JLP_140_18

7. A. Pierro, G. Rossini, P. Gaibani, et al Persistence of anti-chikungunya virus-specific antibodies in a cohort of patients followed from the acute phase of infection after the 2007 outbreak in Italy. New Microbes New Infect. 2015; 7:23-25. doi: 10.1016/j.nmni.2015.04.002

8. Shiran Ajith Paranavitane, Laksiri Gomes, Achala Kamaladasa, et al. Dengue NS1 antigen as a marker of severe clinical disease. BMC infectious diseases 2014; 14:570-4 doi: https://doi.org/10.1186/s12879-014-0570-8

9. Khan DM. Diagnostic methodologies for the dengue viral infection. Int. J.Health allied sci. 2016; 5:133-4 doi: 10.4103/2278-344X.180432

10. Nader Raafat, Stuart D Blacksell, Richard J Maude. A review of dengue diagnostics and implications for surveillance and control, Trans R Soc Trop Med Hyg. 2019; 113(11):653-660 doi: $10.1093 /$ trstmh/trz068 